\title{
Anxiety Assessment in Orofacial Pain Patients
}

\author{
Shital Sudhakar Nikam ${ }^{1}$ Karan Rajendra Shah ${ }^{2}$ Rajeev Madhusudan Gadgil ${ }^{3}$ Dipika Bharat Utekar ${ }^{2}$ \\ Vinayak Umesh Shirsekar ${ }^{2}$
}

${ }^{1}$ Department of Oral Medicine \& Radiology, SMBT Dental College \& Hospital and Postgraduate Research Centre, Sangamner, Maharashtra, India

${ }^{2}$ Department of Oral Medicine \& Radiology, MGV's KBH Dental College \& Hospital, Nashik, Maharashtra, India

${ }^{3}$ Rajeev Gadgil's Dental Clinic, Nashik, Maharashtra, India

\author{
Address for correspondence Shital Sudhakar Nikam, BDS, \\ MDS, Department of Oral Medicine \& Radiology, SMBT \\ Dental College \& Hospital and Postgraduate Research \\ Centre, Sangamner, Ghulewadi 422608, Maharashtra, \\ India (e-mail: drshital1987@gmail.com).
}

Ann Natl Acad Med Sci (India) 2021;57:107-111.

\begin{abstract}
Keywords

- anxiety

- pain

- Modified Dental

Anxiety Scale

- Hospital Anxiety and

Depression Scale

Objectives The aim of the present study was to assess the anxiety level in patients with orofacial pain and to compare it with patients without any orofacial pain.

Materials and Methods The survey-based study was conducted that included a total of 100 patients who were divided into two groups: 50 patients with orofacial pain and 50 patients without pain. Questionnaire in a local language, that is, Marathi, was formulated based on Modified Dental Anxiety Scale (MDAS) and Hospital Anxiety and Depression Scale (HADS). Data was then subsequently collected and evaluated according to the score of MDAS and HADS.

Results A total of 78 patients were evaluated according to the questionnaire survey. Highly significant correlation was found between anxiety level and pain present in patient on the MDAS-anxiety level scale $(p=0.001)$. Also, a significant correlation was observed between anxiety level and pain present in patient on the HADS-anxiety level $(p=0.007)$. A significant correlation was found between gender and pain anxiety level in patients on the MDAS-anxiety level $(p=0.009)$.

Conclusion Anxiety level in patients with orofacial pain can be assessed with MDAS and HADS. Specific types of anxiety-related concerns definitely occur at higher levels in orofacial pain patients in comparison to patients without pain. Greater attention needs to be employed on understanding of anxiety level in orofacial pain patients. This is detrimental in acceptance of treatment by patient and ultimately affects outcome. Anxiety level assessment helps in better understanding of apprehension among the patients with orofacial pain, and enables better delivery of appropriate care and intervention.
\end{abstract}

\section{Introduction}

The decision of delivering different treatment options available to a particular patient depends upon several factors. In particular, it depends on the willingness of the patient to receive a treatment, patient's psychological status, and mental well-being along with cooperation showed by the patient. Various factors are not only responsible for a successful

published online

July 27,2021
DOI https://doi.org/ 10.1055/s-0041-1731971 ISSN $0379-038 \mathrm{X}$ outcome of treatment but also affect long-term prognosis of the treatment delivered. Hence, the whole mental status of the patient needs to be taken into consideration before the start of any dental treatment. This mainly comes under the behavioral sciences and study. ${ }^{1}$ Furthermore, it has to be taken into consideration and admitted that the dental treatments and the whole clinical atmosphere do bring out certain level of anxiety and fear among the patients. Anxiety

(C) 2021. National Academy of Medical Sciences (India).

This is an open access article published by Thieme under the terms of the Creative Commons Attribution-NonDerivative-NonCommercial-License, permitting copying and reproduction so long as the original work is given appropriate credit. Contents may not be used for commercial purposes, or adapted, remixed, transformed or built upon. (https://creativecommons.org/licenses/by-nc-nd/4.0/).

Thieme Medical and Scientific Publishers Pvt. Ltd. A-12, 2nd Floor, Sector 2, Noida-201301 UP, India 
and fear among patients visiting the dental clinic with orofacial pain can be the reasons for the patients to ignore and neglect the necessary dental treatments. ${ }^{2}$ Some patients find dental treatment simply bothersome, while others find it unbearable to the degree of developing specific dental phobias. Several studies have been performed in the past on the anxiety and fear in dental clinics. ${ }^{2}$ Further, since the 19th century, research on the relationship of anxiety with various environmental factors has been a topic of attention. It has been observed that various factors like age, gender, invasive treatments, sharp instruments, presence of carious teeth with pain, red hair individuals, ${ }^{2}$ people with no history of dental treatment, and genetic variations have been alleged to be associated with the development of anxiety and fear for dental treatments, and thereby leading to ignorance and circumvention of the necessary treatments. ${ }^{3}$ It is now understood that anxiety levels will tend to overestimate the possible pain events during any invasive procedures. ${ }^{4}$

In oral health studies, it is estimated that the presence of anxiety is one of the main reasons for poor oral health status of an individual. Also, dental anxiety and fear are said to be common, and their prevalence is $\sim 10 \%{ }^{5}$ Hence, it is imperative for the dentists to evaluate and assess the various causes for dental fear among the patients, and modify or work toward the betterment of the treatment delivered according to the patient's anxiety levels. ${ }^{6,7}$ It is very important to assess the anxiety level in patients as it will help to structure the necessary treatment modifications. ${ }^{8}$ The caregiver can evaluate anxiety of a patient by taking history and performing physical examination, subjecting patients to medical history questionnaire, and through art of observation.

Several self-evaluation questionnaire survey or scoring system are used to assess the anxiety levels among dental patients. ${ }^{9}$ Few of the commonly used scales are the dental anxiety scale (DAS), the Modified Dental anxiety scale (MDAS), Fear Survey Schedule II (FSS-II), Geer Fear Scale, State-Trait Anxiety Inventory, Mood Adjective Check List, Health Locus Scale, Hospital Anxiety and Depression Scale (HADS), and dental fear survey (DFS). ${ }^{10,11}$ In the present study, we aimed to evaluate the anxiety and fear scores in patients with pain and without pain in dental set up. This also emphasizes on better treatment delivery options for the benefits of the patients and for optimum oral health of the patients.

\section{Materials and Methods}

An analytical study was designed on 100 patients who were referred for some kind of dental treatment. The study was conducted in MGV's KBH dental college, Nashik, after obtaining approval from Institutional Ethics Committee. Informed written consent was taken from the participants prior to the start of the study.

The inclusion criteria were presence of orofacial pain in dental setup.

The exclusion criteria were non-cooperative patients, psychiatric patients, and patients not willing to fill the questionnaire. Thus, we included 50 patients with the presence of orofacial pain and 50 patients without orofacial pain.
The present study undertook two anxiety evaluation scales, namely the MDAS and the HADS. Questionnaire was formulated based on MDAS and HADS and translated in local language. Fifty patients with pain, and 50 patients without pain were given the questionnaire for assessment of anxiety and fear scores.

In 1995, Humphris et al introduced MDAS, a modified version of the Corah Dental Anxiety Scale, by adding a new item. It consisted of five items, self-report to measure dental anxiety. A new item that he considered was very essential to have was local anesthesia..$^{10}$ The MDAS is internally consistent with Cronbach coefficient $(\alpha)$ of 0.93 , and has good reliability with intraclass correlation coefficient of $0.93 .{ }^{12}$

The MDAS consisted of five multiple-choice items dealing with the patient's subjective reaction about going to the dentist's office, waiting in the dentist's office for the procedure, anticipating drilling, scaling, and local anesthetic injection in gums. Points are assigned to each subject choice, which ranged from one point (not anxious) to five points (extremely anxious). Total scores ranged between 5 and 25. A patient with a score of 19 and above was considered as extremely anxious individual. The questions of MDAS were translated in local language that patients can understand (i.e., Marathi) are as follows:

1. If you have to go to the dentist tomorrow how would you feel about it?

2. When you are waiting in the dentist's office for your turn in the chair, how do you feel?

3. When you are waiting in dentist's chair waiting while the dentist gets the drill ready to begin working on your teeth, how do you feel?

4. Imagine you are in the dentist's chair to have your teeth cleaned. While you are waiting and the dentist or hygienist is getting out instruments which will be used to scrape your teeth around the gums, how do you feel?

5. If you were about to have local anesthetic injection in gums, how would you feel?

The HADS was developed by Zigmond and Snaith in $1983 .{ }^{8}$ The HADS is a self-report rating scale of 14 items on a 4-point Likert scale (range $0-3$ ). It is designed to measure anxiety and depression ( 7 items for each subscale). The total score is the sum of the 14 items, and for each subscale, the score is the sum of the respective seven items (ranging from 0 to 21$).^{8}$ The HADS with anxiety and depression subscales is internally consistent, with values of Cronbach's coefficient $(\alpha)$ being 0.80 and 0.76 , for anxiety and depression, respectively. The reliability for the same is 0.92 for HADS anxiety scale, and 0.88 for HADS depression scale. ${ }^{13}$ The HADS included responses for the following questions that were translated in local language that patients can understand (i.e., Marathi):

1. I feel tensed or "wound up."

2. I still enjoy the things I used to enjoy.

3. I get a sort of frightening feeling as if something awful is about to happen.

4. I can laugh and see the funny side of things.

5. Worrying thoughts go through my mind. 
6. I feel cheerful.

7. I can sit at ease and feel relaxed.

8. I feel as if I am slowed down.

9. I get a sort of frightened feeling like "butterflies" in the stomach.

10. I have interest in my appearance.

11. I feel restless as I have to be on the move.

12. I look forward with enjoyment to things.

13. I get sudden feelings of panic.

14. I can enjoy a good book or radio or TV program.

After all the responses were filled by the patient, the forms were collected. Incomplete forms were excluded and considered as dropouts.

\section{Statistical Analysis}

All the data was collected and appropriate statistical test was applied for analysis. After collection of all the questionnaires, the data was segregated, tabulated, and analyzed using SPSS software version 15 . Results subjected to statistical analysis using descriptive statistics were applied to all variables in the study. Chi-squared test was performed to evaluate the association between anxiety level and pain present in a patient on MDAS-anxiety level and HADS-anxiety level. For all the tests, the level of significance was considered at $p<0.05$.

\section{Results}

A total of 78 patients were evaluated, and 22 were considered as dropouts. Out of these patients, 42 were male and 36 were female. Pain was present in $58 \%$ of the patients, and absent in $42 \%$ patients among both the groups (-Table $\mathbf{1}$ ).

The mean and standard deviation of MDAS scores were 10.53 and 4.150, respectively, in patients without pain. The mean and standard deviation of MDAS scores were 18.62 and 2.74 , respectively, in patients with pain.

Table 1 Mean and standard deviation of anxiety scores in the MDAS in both the groups

\begin{tabular}{|l|l|l|}
\hline & MDAS-mean & $\begin{array}{l}\text { MDAS-standard } \\
\text { deviation }\end{array}$ \\
\hline Patients without pain & 10.53 & 4.150 \\
\hline Patients with pain & 18.62 & 2.74 \\
\hline
\end{tabular}

Abbreviation: MDAS, Modified Dental Anxiety Scale.

Table 2 Mean and standard deviation of anxiety scores in the HADS in both the groups for anxiety

\begin{tabular}{|l|l|l|}
\hline & $\begin{array}{l}\text { HADS-mean } \\
\text { (anxiety) }\end{array}$ & $\begin{array}{l}\text { HADS-standard } \\
\text { deviation } \\
\text { (anxiety) }\end{array}$ \\
\hline $\begin{array}{l}\text { Patients without } \\
\text { pain }\end{array}$ & 2.69 & 1.95 \\
\hline Patients with pain & 6.71 & 1.88 \\
\hline
\end{tabular}

Abbreviation: HDAS, Hospital Anxiety and Depression Scale.
According to this, the anxiety level in patients with pain was greater than in patients without pain on MDAS (-Table 2).

The mean and standard deviation of HADS scores for anxiety were 2.69 and 1.95 , respectively, in patients without pain, and the mean and standard deviation of HADS scores for anxiety were 6.71 and 1.88 , respectively, in patients with pain (-Table 3).

The mean and standard deviation of HADS scores for depression were 3.23 and 2.209, respectively, in patients

Table 3 Mean and standard deviation in depression scores in the HADS in both the groups for depression

\begin{tabular}{|l|l|l|}
\hline & $\begin{array}{l}\text { HADS-mean } \\
\text { (depression) }\end{array}$ & $\begin{array}{l}\text { HADS-standard } \\
\text { deviation } \\
\text { (depression) }\end{array}$ \\
\hline Patients without pain & 3.23 & 2.209 \\
\hline Patients with pain & 4.09 & 1.676 \\
\hline
\end{tabular}

Abbreviation: HDAS, Hospital Anxiety and Depression Scale.

without pain, and the mean and standard deviation of HADS scores for depression were 4.09 and 1.676, respectively, in patients with pain in case of depression scores. The anxiety and depression level in patients with pain was greater than in patients without pain on MDAS. A significant correlation was found between the anxiety level and pain present in patients on MDAS ( $p=0.001 ;$ - Fig. 1A). A significant correlation was observed between the anxiety level and pain present in patients on HADS-anxiety level $(p=0.007 ;-$ Fig. 1B). A significant correlation was found between gender and pain anxiety level in patients on MDAS-anxiety level $(p=0.009)$. The anxiety level score on MDAS was higher in female patients with pain compared with that of in male patients ( - Fig. 2).

\section{Discussion}

It has been observed in the present study that anxiety level is related to orofacial pain in the studied patients. MDAS is more significant than HADS in assessing anxiety. Anxiety level was observed to be related to gender in the studied population. Further, no significant correlation was found between age and the level of anxiety on both the scales in the studied population. An earlier study has shown that women frequently have higher levels of dental anxiety as compared with men. ${ }^{9}$ Highly anxious dental patients seem to have experienced reality to be even worse than they expected.

According to the study conducted by Doerr et $a l,{ }^{5}$ the prevalence of dental anxiety was $10 \%$ and regression analysis revealed six factors to be associated with dental anxiety: unfavorable attitudes toward dentists, infrequent checkups, dissatisfaction with one's mouth, small numbers of filled surfaces, being female, and lower income. ${ }^{5}$

Knowledge of a patient's anxiety before treatment can be an aid to the dentist in two ways. First, he/she can become aware of what to expect from the patient, and he/she can take appropriate measures to help alleviate the anxiety of the 


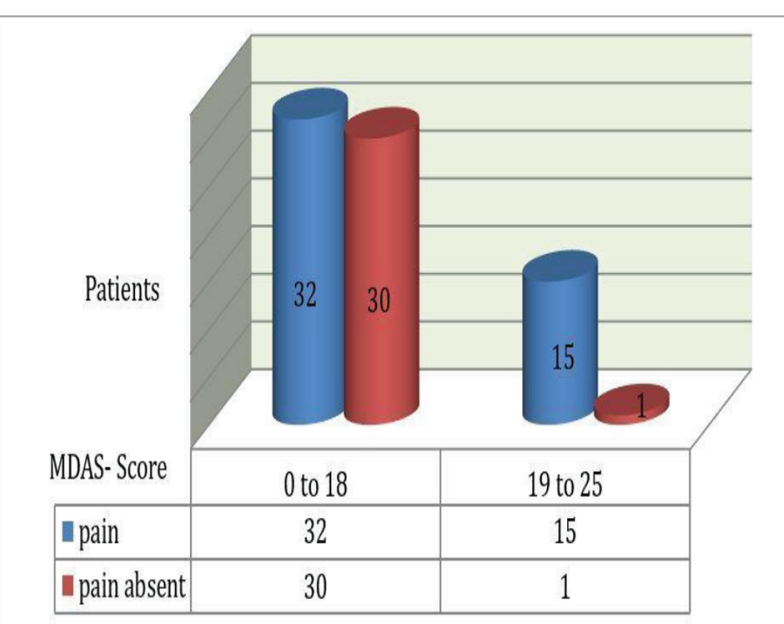

A

Fig. 1 (A) Correlation found between anxiety level and pain present in patient on Modified Dental Anxiety Scale (MDAS). (B) Correlation found between anxiety level and pain present in patient on Hospital Anxiety and Depression Scale (HADS)-anxiety level.

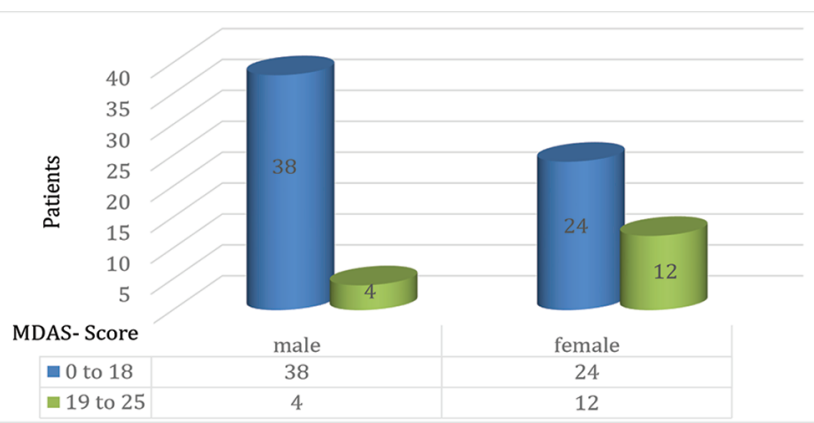

Fig. 2 Correlation found between gender and pain anxiety level in patient on Modified Dental Anxiety Scale (MDAS)-anxiety level.

patient. ${ }^{14}$ Research on dental anxiety has been an important topic for several decades..$^{15}$ It has been stated that anxiety and fear have a considerable impact on utilization of dental services. van Wijk and Hoogstraten reported that anxious people tend to overestimate pain. ${ }^{4}$ Anxious individuals have also been previously reported to avoid dental care as much as they can. ${ }^{3}$

In the present study, the anxiety levels were compared between orofacial pain patients and patients without pain. A similar study was performed by McNeil et al who used the fear of pain questionnaire III to evaluate fear levels in patients with pain as compared with the controls. The study reported that in patients with pain, the fear for dental treatment was greater as compared with control patients. ${ }^{16}$

Few studies have reported the correlation of temporomandibular joint disorder pain with increased anxiety levels in patients. ${ }^{17,18}$ The relationship between anxiety and chronic orofacial pain of temporomandibular disorder in a group of university students was studied by Monteiro et al. ${ }^{17}$ In this study, it was concluded that chronic orofacial pain of temporomandibular joint disorders could be present in university students and anxiety may be related to it. However, no

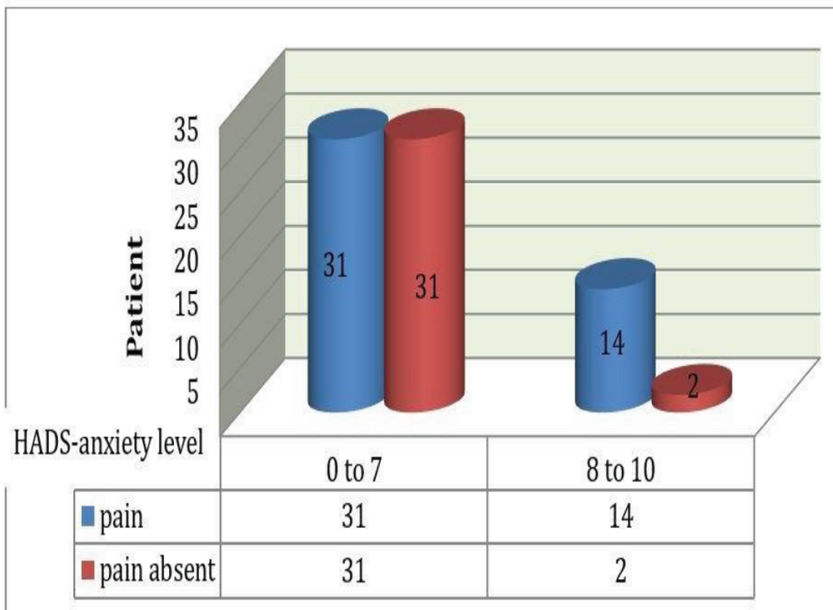

B

significant correlation was found to state-anxiety levels and chronic orofacial pain degrees. ${ }^{17}$

Our results are in line with the findings reported by Klages et al which demonstrated that subjects, in general, expect more pain than they experience, and that this effect is stronger in a group with higher dental anxiety scores. ${ }^{19}$ Since dental pain can induce anxiety, and anxiety leads to overestimation of orofacial pain, it is assumed that an overestimation of either the pain, or the fear of it, is particularly present in a group with subjects scoring high on dental anxiety, such as highly anxious dental patients. ${ }^{19}$

However, another study of adults aged 50 years and older found no difference in dental anxiety according to sex, but it reported that elder patients had less anxiety and fear levels as compared with the group of patients with younger population..$^{20}$ Further, as reported by McCracken et al, elevated levels of anxiety about pain contribute to disability and interference with life activities and functioning, it may be important for clinicians to intervene to reduce anxiety-related distress in these patients. ${ }^{21}$ People who are predisposed to respond fearfully to pain are at an increased risk of ending up in a vicious circle of anxiety, fear of pain, and avoidance of dental treatment. ${ }^{21}$ Moore et al studied the contribution of embarrassment to phobic dental anxiety and reported that embarrassment is a complex dental anxiety manifestation with qualitativedifferences..$^{22}$

\section{Scope of the Study}

The present study was a cross-sectional survey. The relationship between anxiety and dental fear is a complex correlation and may differ from person to person. Hence, more research needs to be performed in this field considering behavioral science. Research in the evaluation of patients will help caregivers to find out various behavior management modifications for better implementation of dental treatments specially to 
the more scared or anxious patients. This will not just help in self-evaluation but will also help to reduce dental negligence. It would also help in delivering the different treatments in a more convenient and efficient way. Ultimately, it will lead to the betterment of general health and good oral health of the patient.

\section{Conclusion}

Anxiety level in patient can be assessed significantly with MDAS and HADS. Particular types of anxiety-related concerns do indeed occur at higher levels in orofacial pain patients in comparison to patients without pain. Greater attention should be placed on understanding anxiety in orofacial pain patients. All must admit the fact that dental treatment is in fact considered as dental treatment by most of the patients. The use of noisy drills, noisy suction, sharp instruments, third molar surgeries, and injections are some of the common reasons that can induce fear among anxious patients. All these factors bring in the dental fear, dental anxiety, or dental phobia among many people. This will indirectly hamper the effective treatment as apprehensive patients do not let the dentist perform adequate implementation of their work. Hence, it becomes very necessary to first evaluate the patients state of mind in case of anxiety and fear. Accordingly, several measures can be implemented for the required work atmosphere and to reduce anxiety level among patient. From the present study, we can conclude that MDAS and HADS can be effectively used in the evaluation of patient's fear and anxiety levels and should be used to assess anxious patient with orofacial pain.

\section{Conflict of Interest}

None declared.

\section{Acknowledgments}

The authors wish to thank all the participants, the institute authorities, and faculty members of the department.

\section{References}

1 Newton JT, Buck DJ. Anxiety and pain measures in dentistry: a guide to their quality and application. J Am Dent Assoc 2000;131(10):1449-1457

2 Binkley CJ, Beacham A, Neace W, Gregg RG, Liem EB, Sessler DI. Genetic variations associated with red hair color and fear of dental pain, anxiety regarding dental care and avoidance of dental care. J Am Dent Assoc 2009;140(7):896-905

3 Raciene R. Dental fear among teenagers. individual anxiety factors. Stomatologija 2004;6:118-121

4 van Wijk AJ, Hoogstraten J. Experience with dental pain and fear of dental pain. J Dent Res 2005;84(10):947-950
5 Doerr PA, Lang WP, Nyquist LV, Ronis DL. Factors associated with dental anxiety. J Am Dent Assoc 1998;129(8):1111-1119

6 Smith TA, Heaton LJ. Fear of dental care: are we making any progress. ? J Am Dent Assoc 2003;134(8):1101-1108

7 Davis CE, Stockstill JW, Stanley WD, Wu Q. Pain-related worry in patients with chronic orofacial pain. J Am Dent Assoc 2014;145(7):722-730

8 Michopoulos I, Douzenis A, Kalkavoura C, et al. Hospital anxiety and depression scale (HADS): validation in a Greek general hospital sample. Ann Gen Psychiatry 2008;7:4

9 Heaton LJ, Carlson CR, Smith TA, Baer RA, de Leeuw R. Predicting anxiety during dental treatment using patients'self-reports: less is more. J Am Dent Assoc 2007;138(2):188-195

10 Humphris GM, Dyer TA, Robinson PG. The modified dental anxiety scale: UK general public population norms in 2008 with further psychometrics and effects of age. BMC Oral Health 2009;9:20

11 Coolidge T, Arapostathis KN, Emmanouil D, et al. Psychometric properties of Greek versions of the Modified Corah Dental Anxiety Scale (MDAS) and the Dental Fear Survey (DFS. BMC Oral Health 2008;8:29

12 Mykletun A, Stordal E, Dahl AA. Hospital Anxiety and Depression (HAD) scale: factor structure, item analyses and internal consistency in a large population. $\mathrm{Br}$ J Psychiatry 2001;179:540-544

13 Newton JT, Edwards JC. Psychometric properties of the modified dental anxiety scale: an independent replication. Community Dent Health 2005;22(1):40-42

14 Amir A, Kamate S, Gupta P, Gupta A, Singh J, Singh S. Assessment of dental anxiety using MDAS (Modified Dental Anxiety Scale) among students in Bareilly City-A cross sectional study. Int J Contemp Med Res 2018;5:23-26

15 Pawlicki RE. Psychological/behavioral techniques in managing pain and anxiety in the dental patient. Anesth Prog 1991;38(4-5):120-127

16 McNeil DW, Au AR, Zvolensky MJ, McKee DR, Klineberg IJ, Ho CC. Fear of pain in orofacial pain patients. Pain 2001;89(2-3):245-252

17 Monteiro DR, Zuim PR, Pesqueira AA, Ribeiro Pdo, Garcia AR. Relationship between anxiety and chronic orofacial pain of temporomandibular disorder in a group of university students. J Prosthodont Res 2011;55(3):154-158

18 Giannakopoulos NN, Keller L, Rammelsberg P, Kronmüller KT, Schmitter M. Anxiety and depression in patients with chronic temporomandibular pain and in controls. J Dent 2010;38(5):369-376

19 Klages U, Ulusoy O, Kianifard S, Wehrbein H. Dental trait anxiety and pain sensitivity as predictors of expected and experienced pain in stressful dental procedures. Eur J Oral Sci 2004;112(6):477-483

20 Locker D, Liddell AM. Correlates of dental anxiety among older adults. J Dent Res 1991;70(3):198-203

21 McCracken LM, Zayfert C, Gross RT. The Pain Anxiety Symptoms Scale: development and validation of a scale to measure fear of pain. Pain 1992;50(1):67-73

22 Moore R, Brødsgaard I, Rosenberg N. The contribution of embarrassment to phobic dental anxiety: a qualitative research study. BMC Psychiatry 2004;4:10 